\title{
Application of Kinematic Wave Equations to Border Irrigation Design
}

\author{
Rama S. RaM*; VIJAY P. Singh†
}

\begin{abstract}
Accuracy of the kinematic wave $(K W)$ approximation was tested on 31 experimental irrigation borders by computing the $K W$ number and its modified version. In a majority of cases, this approximation was found to be sufficiently accurate. A $K W$ model, reported previously, was used to derive dimensionless advance and recession curves for application to border irrigation design. These curves can be developed for a wide range of design variables and parameters for ready practical use. A step by step design procedure, based on this model is presented. Its validity was tested by comparing observed irrigation efficiencies with those computed by the model. A close agreement between computed and observed efficiencies suggests that the $K W$ model is reasonably accurate. Its simplicity and physical basis may justify its large-scale field application.
\end{abstract}

\section{Introduction}

A knowledge of advance, recession, distribution of depth of water and distribution of infiltrated water is required for optimal design of border irrigation. One way to determine these design variables is by using mathematical models. There are many models of border irrigation. Most of these models can be classified in order of increasing complexity as (1) storage models, (2) kinematic models (3) zero-inertia models, and (4) hydrodynamic models. A recent study by $\operatorname{Ram}^{1}$ presented a comprehensive survey of these modcls. Bassett, Fangmeier and Strelkoff ${ }^{2}$ have discussed the current state of the art of hydraulics of surface irrigation.

This study employs a kinematic wave $(K W)$ model. Sherman and Singh, ${ }^{\mathbf{3}, \mathbf{4}}$ and Singh and Sherman ${ }^{5}$ provided a comprehensive mathematical treatment of $K W$ modelling of surface irrigation. Singh and $\operatorname{Ram}^{6}$ tested this $K W$ model by using data from 31 experimental borders and concluded that the model was sufficiently accurate for predicting advance and horizontal recession; the model is not capable of accommodating vertical recession. This concurred with the earlier studies by Smith, ${ }^{7}$ and Chen, McCann and Singh. ${ }^{\mathbf{8}}$ However, these studies did not provide quantitative estimates regarding the accuracy of the $K W$ model. Neither were irrigation efficiencies, required for irrigation design, computed. In this study we compute the kinematic wave number ${ }^{9}$ and its modified version ${ }^{10}$ indicating the model accuracy for all the data sets used in that study.

Although the $K W$ approximation has been employed in a number of studies on surface irrigation, ${ }^{3-5.7 .8 .11-14}$ its application to actual border irrigation design does not appear to have been reported. One of the objectives of designing a border irrigation system is to make optimum use of the water available for irrigating a given crop. In practice there exists a wide range of inflow stream sizes, irrigation durations and border lengths for which this objective should be achieved. This can be done more conveniently by employing dimensionless solutions of $K W$ equations. We attempt to develop a design procedure based on dimensionless solutions of the $K W$ model. The design procedure is tested by computing irrigation efficiencies for a typical depth of application of $0.1 \mathrm{~m}$ for data from 31 experimental borders, and by comparing them with observations.

*Department of Mathematics, Alcorn State University, Lorman, MS 39096, U.S.A.

tDepartment of Civil Engineering, Louisiana State University, Baton Rouge, LA 70803. U.S.A.

Received 15 November 1983; accepted in revised form 9 August 1984 


\section{NOTATION}

a Dimensionless exponent in the Kostyakov infiltration equation (Eqn 4)

$A_{s} \quad$ Dimensionless bulk density of soil

$d_{a} \quad$ Depth of water applied $(L)$

$d_{d} \quad$ Average absolute numerical deviation of stored depth from the average depth of water stored in root zone along the border $(L)$

$d_{n} \quad$ Depth of water needed in the root zone $(L)$

$d_{s} \quad$ Average depth of water stored in the root zone $(L)$

$D_{r} \quad$ Depth of root zone $(L)$

$E_{a} \quad$ Application efficiency (dimensionless)

$E_{d} \quad$ Distribution efficiency (dimensionless)

$E_{s} \quad$ Storage efficiency (dimensionless)

$f \quad$ Capacity rate of infiltration $\left(L T^{-1}\right)$

$F_{o} \quad$ Froude number (dimensionless)

$G \quad$ Normal depth of flow at the upstream end $(L)$

$h \quad$ Depth of flow $(L)$

$h^{*} \quad$ Normalized depth of flow (dimensionless)

$K \quad$ Parameter in the Kostyakov infiltration equation (Eqn $4, L T^{- \text {a }}$ )

$K_{1} \quad$ Kinematic flow number (dimensionless)

$K_{2} \quad$ Dimensionless number corresponding to the momentum term associated with infiltration

$L \quad$ Border length $(L)$

$n \quad$ Dimensionless exponent in the depth discharge relation (Eqn 2)

$n_{m} \quad$ Manning's roughness coefficient $\left(L^{-1 / 3} T\right)$

$P_{w} \quad$ Soil moisture deficit in percent (dimensionless)

$P_{1} \quad$ Modified kinematic flow number (dimensionless)

$P_{2} \quad$ Modified dimensionless number corresponding to the momentum term associated with infiltration

$q \quad$ Inflow rate per unit width $\left(L^{2} T^{-1}\right)$

$q_{0} \quad$ Constant inflow rate per unit width at the upstream end $\left(L^{2} T^{-1}\right)$

$q^{*} \quad$ Normalized inflow rate (dimensionless)

Q Discharge per unit width $\left(L^{2} T^{-1}\right)$

$S_{f} \quad$ Slope of the energy line (dimensionless)

$S_{o} \quad$ Bed slope (dimensionless)

$t \quad$ Time $(T)$

$t^{*} \quad$ Normalized time (dimensionless)

$T_{o} \quad$ Normalizing time $(T)$

$T_{1} \quad$ Duration of irrigation $(T)$

$T_{1}^{*} \quad$ Normalized duration of irrigation (dimensionless)

$v \quad$ Velocity of flow $\left(L T^{-1}\right)$

$V_{0} \quad$ Normalizing velocity $\left(L T^{-1}\right)$

$v^{*} \quad$ Normalized velocity (dimensionless)

$x$

Distance along the border measured from the upstream end $(L)$

$x^{*} \quad$ Normalized distance along the border measured from the upstream end (dimensionless)

$X_{o} \quad$ Normalizing distance $(L)$

$\beta \quad$ Kinematic friction parameter $\left(L^{1-n} T^{-1}\right)$

$\beta_{o} \quad$ Kinematic friction parameter in the relation between normal depth of flow at the upstream and the corresponding inflow $\left(L^{1-n} T^{-1}\right)$

$\xi \quad$ Time history of advance front $(T)$

$\xi^{*} \quad$ Normalized time history of advance front (dimensionless)

$\tau \quad$ Infiltration opportunity time $(T)$ 


\section{Kinematic wave model}

The $K W$ modcl, developed by Sherman and Singh,,$^{\mathbf{3 . 4}}$ can be expressed for flow over a plane with a small slope and porous bed on a unit width basis as

$$
\begin{gathered}
\frac{\partial h}{\partial t}+\frac{\partial Q}{\partial x}=-f[t-\xi(x)] \\
Q=v(x, t) h(x, t)=\beta h^{n} \\
\frac{d \xi(x)}{d x}=\left\{\beta h^{n-1}[\mathrm{x}, \xi(x)]\right\}^{-1}
\end{gathered}
$$

in which $h(x, t)$ is depth of flow, $Q(x, t)$ is discharge, $v$ is velocity of flow, $f(\tau)$ is infiltration rate, $\tau=t-\xi(x)$, infiltration opportunity time, and $n$ and $\beta>0$ are $K W$ parameters; $n$ varies from 1 to 3 inclusive. From now on, a symbol will be defined when it appears for the first time. For easy referencing, all the symbols are given in the Notation. Note that $t=\xi(x)$ denotes the time history of the advance front or the advance function. The infiltration rate $f(\tau)$ is assumed to depend only on the difference $\tau$ between the total elapsed time and the advance time, that is, it is timedependent but independent of $x$ for $x>0$. It can be determined by the Kostyakov equation ${ }^{15}$ as

$$
f(\tau)=\left\{\begin{array}{l}
a K \tau_{c}^{a-1}, 0 \leqslant \tau \leqslant \tau_{c} \\
a K \tau^{a-1}, \tau \geqslant \tau_{c}
\end{array}\right.
$$

$\tau_{c}$ is a constant and can be specified for a given soil. It was taken to be $0.1 \mathrm{~min}$ in this study. The exponent $a$ varies between 0 and 1 , and $K>0$ is a parameter.

The initial conditions can be expressed as

$$
\begin{gathered}
h(0, t)=h_{o}(t), \quad 0 \leqslant t \leqslant T_{1} \\
h(0, t)=0, \quad t \geqslant T_{1} \\
\xi(0)=0
\end{gathered}
$$

Where $T_{1}$ is duration of irrigation. One can also define initial conditions in terms of discharge at the upstream end. $Q(0, t)=q(t), 0 \leqslant t \leqslant T_{1} ; Q(0, t)=0, t \geqslant T_{1} q(t)$ specifies the time-varying rate of inflow.

\subsection{Dimensionless solutions}

A principal advantage of dimensionless solutions is the reduced number of parameters contained in them. Further, the dimensionless solutions are independent of the system of units used. The dimensionless variables appear as ratios with respect to normalizing quantities. Therefore, it is easy to interpret the effect of proportional variations of one variable on the other. Because of the reduced size of the variables, dimensionless solutions are easy for graphical representation. To reduce Eqns $1-3$, the following normalizing quantities are defined:

$q_{o}=$ constant inflow at the upstream end

$V_{o}=$ normal velocity at the upstream end

$G=$ normal depth of flow at the upstream end corresponding to the constant inflow $q_{o}$, and can be determined as

$$
\begin{aligned}
& G=\left(\beta_{o} q_{o}\right)^{0.6} \\
& \beta_{o}=n_{m} / S_{o}^{0.5}
\end{aligned}
$$

where $n_{m}$ is Manning's roughness coefficient and $S_{o}$ bed slope. 
$T_{o}=$ normalizing distance defined as

$$
T_{o}=(G / K)^{1 / a}
$$

$X_{o}=$ normalizing distance defined as

$$
X_{o}=V_{o} T_{o}
$$

By using the normalizing quantities, the dimensionless variables can be defined as

$$
q^{*}=\frac{q}{q_{o}}, h^{*}=\frac{h}{G}, v^{*}=\frac{v}{V_{o}}, x^{*}=\frac{x}{X_{o}}, t^{*}=\frac{t}{T_{o}}, \tau^{*}=\frac{\tau}{T_{o}}, T_{1}^{*}=\frac{T_{1}}{T_{o}}
$$

By substituting dimensionless variables in Eqns 1 and 3 and coupling Eqns 1 and 2, we obtain

$$
\begin{gathered}
\frac{\partial h^{*}}{\partial t^{*}}+n h^{* n-1} \frac{\partial h^{*}}{\partial x^{*}}+a\left(\tau^{*}\right)^{a-1}=0 \\
\frac{d \xi^{*}\left(x^{*}\right)}{d x^{*}}=\frac{1}{h^{* n-1}}, \xi^{*}(0)=0
\end{gathered}
$$

These equations are subject to

$$
\begin{array}{ll}
h^{*}\left(0, t^{*}\right)=h_{o}^{*}\left(t^{*}\right), & \\
h^{*}\left(0, t^{*}\right)=0, & t^{*} \geqslant T_{1}^{*} \leqslant T_{1}^{*} \\
\xi^{*}(0)=0 &
\end{array}
$$

The solution of Eqns 11 and 12 subject to Eqn 13 consists of two parts. The first part, representing the advance and storage phases, is for $0 \leqslant t^{*} \leqslant T_{1}^{*}$. The second part, representing the recession phase, is for $t^{*} \leqslant T_{1}^{*}$. The solution for the first part was obtained numerically by the kinematic wave train $(K W T)$ method. This is described by Ram, Singh and Prasad ${ }^{14}$ and Singh and Ram. ${ }^{6}$ This requires specification of grid spacing which was taken as $1.524 \mathrm{~m}$ and ratio of advance tip depth to normal depth of flow which was taken as $0 \cdot 05$. The solution for the second part was obtained explicitly in a sequential manner, and is described by Ram, Singh and Prasad. ${ }^{14}$ This method of solution of Eqns 11-13 is part numerical and part analytical, and is simpler and more efficient than the numerical method proposed by Sherman and Singh, ${ }^{4}$ and Singh and Sherman. ${ }^{5}$

\subsection{Experimental data}

Thirty-one sets of data, as given in Tables $1-3$, were used in this study. Four sets of data, designated as Roth-8-Roth-11, arc duc to Roth, ${ }^{16}$ and Roth et al. ${ }^{17}$ These data were collected on non-vegetated borders (soil classified as sandy loam, bulk density 1.4). Nine sets of data, referred to as K-1-K-9, were collected for irrigations on vegetated borders (bromegrass, bromegrass alfalfa, grain sorghum, barley), and are due to Kincaid ${ }^{\mathbf{1}}$. Eighteen sets of data, designated as R-1-R-18, are due to Ram. ${ }^{19-20}$ The data sets R-1-R-9 were collected on nonvegetated borders, and R-10-R-18 on vegetated (wheat crop) borders. For complete details on these data, see the cited references. 
R. S. RAM; V. P. SINGH

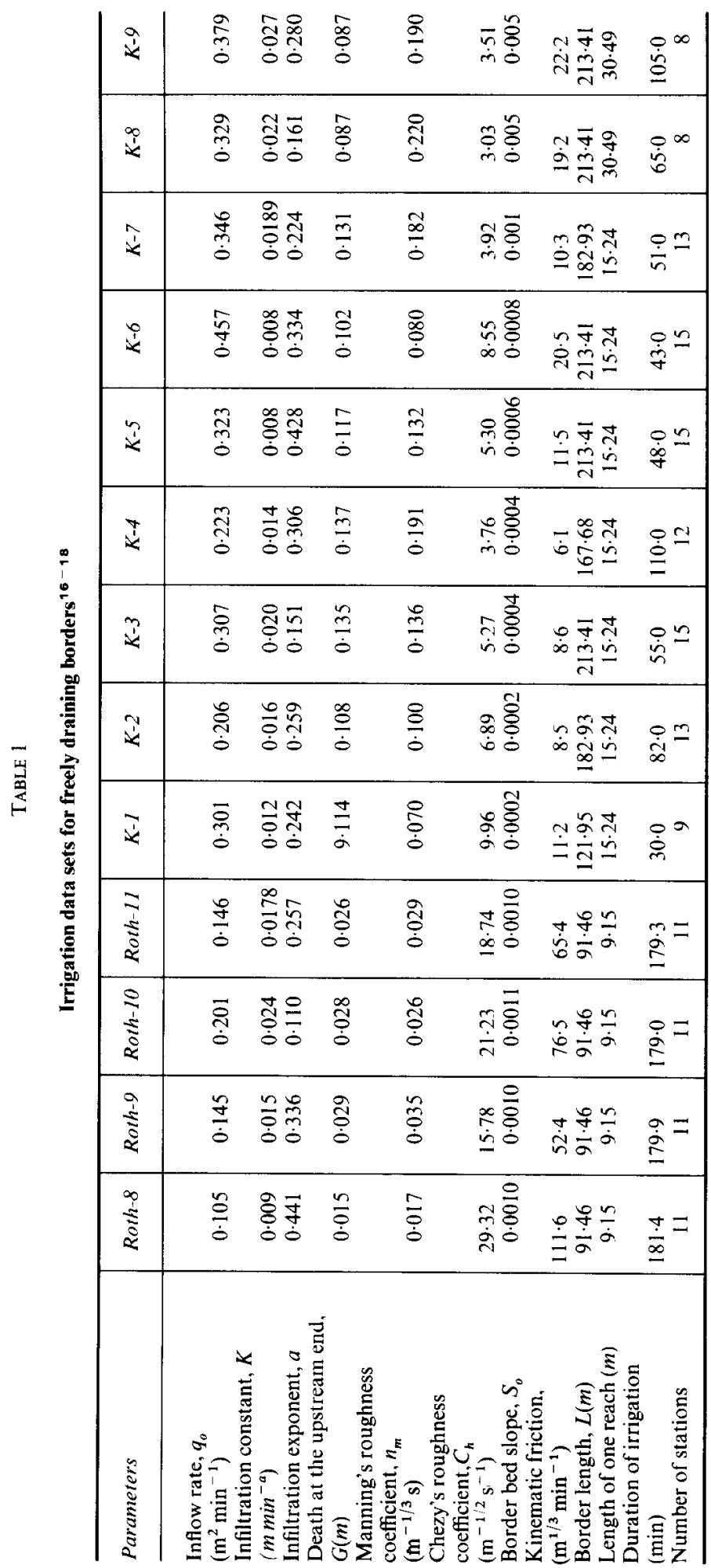


TABLE 2

Irrigation data sets for non-vegetated borders with bund at the downstream end ${ }^{19,20}$

\begin{tabular}{|c|c|c|c|c|c|c|c|c|c|}
\hline Parameters & $R-I$ & $R-2$ & $R-3$ & $R-4$ & $R-5$ & $R-6$ & $R-7$ & $R-8$ & $R-9$ \\
\hline $\begin{array}{l}\text { Inflow rate, } q_{o} \\
\left(\mathrm{~m}^{2} \min ^{-1}\right)\end{array}$ & $0 \cdot 160$ & $0 \cdot 120$ & 0.080 & $0 \cdot 160$ & $0 \cdot 120$ & 0.080 & $0 \cdot 160$ & $0 \cdot 120$ & $0 \cdot 080$ \\
\hline $\begin{array}{l}\text { Infiltration } \\
\text { constant, } K \\
\left.\text { (m min } \min ^{-a}\right)\end{array}$ & 0.004 & 0.005 & 0.005 & 0.005 & 0.005 & 0.004 & 0.004 & 0.003 & 0.006 \\
\hline Infiltration & & & & & & & & & \\
\hline exponent, $a$ & 0.567 & 0.574 & 0.590 & 0.605 & 0.588 & 0.615 & 0.690 & 0.690 & 0.527 \\
\hline $\begin{array}{l}\text { Depth at the } \\
\text { upstream end, } G(m)\end{array}$ & 0.026 & 0.023 & 0.015 & 0.035 & 0.033 & 0.037 & $0 \cdot 050$ & 0.039 & 0.031 \\
\hline $\begin{array}{l}\text { Manning's roughness } \\
\text { coefficient, } n_{m} \\
\left(\mathrm{~m}^{-1 / 3} \mathrm{~s}\right)\end{array}$ & 0.059 & 0.066 & 0.048 & 0.077 & 0.092 & $0 \cdot 100$ & 0.080 & 0.071 & 0.073 \\
\hline $\begin{array}{l}\text { Chezy's roughness } \\
\text { coefficient, } C_{h}\end{array}$ & 00.7 & 1000 & $60+6$ & rot & 0.092 & 0100 & 0000 & 0011 & 0.07 \\
\hline$\left(m^{-1 / 2} s^{-1}\right)$ & $9 \cdot 26$ & $8 \cdot 11$ & $10 \cdot 26$ & $7 \cdot 44$ & $6 \cdot 15$ & 5.49 & 7.54 & $8 \cdot 21$ & 7.72 \\
\hline Border bed slope, $S_{o}$ & 0.005 & 0.005 & 0.005 & 0.003 & 0.003 & 0.003 & 0.001 & 0.001 & 0.001 \\
\hline $\begin{array}{l}\text { Kinematic friction, } \\
\left(\mathrm{m}^{-1 / 3} \mathrm{~min}^{-1}\right)\end{array}$ & 72.4 & $64 \cdot 5$ & 87.7 & $47 \cdot 7$ & $35 \cdot 7$ & $32 \cdot 9$ & $23 \cdot 6$ & $26 \cdot 8$ & $26 \cdot 2$ \\
\hline Border length, $L(m)$ & $100 \cdot 0$ & $100 \cdot 0$ & $100 \cdot 0$ & $100 \cdot 0$ & $100 \cdot 0$ & $100 \cdot 0$ & $100 \cdot 0$ & 100.0 & $100 \cdot 0$ \\
\hline $\begin{array}{l}\text { Length of one } \\
\text { reach }(m)\end{array}$ & $10 \cdot 0$ & $10 \cdot 0$ & 10.0 & $10 \cdot 0$ & $10 \cdot 0$ & $10 \cdot 0$ & $10 \cdot 0$ & $10 \cdot 0$ & $10 \cdot 0$ \\
\hline $\begin{array}{l}\text { Length from the } \\
\text { upstream end where } \\
\text { impounding starts }\end{array}$ & $80 \cdot 0$ & $82 \cdot 0$ & $88 \cdot 0$ & $70 \cdot 0$ & $70 \cdot 0$ & $74 \cdot 5$ & $35 \cdot 0$ & $38 \cdot 0$ & $40-5$ \\
\hline $\begin{array}{l}\text { Duration of } \\
\text { irrigation (min) }\end{array}$ & $22 \cdot 5$ & 37.0 & $59 \cdot 0$ & $35 \cdot 5$ & $50 \cdot 0$ & $74 \cdot 0$ & $50 \cdot 0$ & $59 \cdot 0$ & $95 \cdot 0$ \\
\hline Number of stations & 11 & 11 & 11 & 11 & 11 & 11 & 11 & 11 & 11 \\
\hline
\end{tabular}

\subsection{Parameter estimation}

The $K W$ model, expressed by Eqns $1-3$, contains two unknown infiltration parameters $K$ and $a$ of the Kostyakov equation and two unknown $K W$ parameters $n$ and $\beta$. The values of these parameters for each data set are given in Tables 1-3. The infiltration parameters were estimated by using a volume balance method. The $K W$ parameters were estimated by representing Eqn 2 by Manning's equation. This yields $n=5 / 3$ and $\beta$ as expressed by

$$
\beta=S_{f}^{0.5} / n_{m}
$$

where $S_{f}$ is slope of the energy line or friction slope.

\section{Validation of the $K W$ model}

Criteria for assessing accuracy of the $K W$ model can be derived from dimensionless forms of $\mathrm{St}$ Venant equations of shallow flow over a border as proposed by Katopodes and Strelkoff. ${ }^{10}$ They, following the work of Woolhiser and Liggett, ${ }^{9}$ derived the following parameters:

$$
\begin{aligned}
& P_{1}=K_{1} F_{o}^{2} \\
& P_{2}=K_{2} F_{o}^{2}
\end{aligned}
$$


TABLE 3

Irrigation data sets for vegetated (wheat crop) borders with bund at the downstream end ${ }^{10,20}$

\begin{tabular}{|c|c|c|c|c|c|c|c|c|c|}
\hline Parameters & $R-10$ & $R-H$ & $R-12$ & $R-13$ & $R-14$ & $R-15$ & $R-16$ & $R-17$ & $R-18$ \\
\hline $\begin{array}{l}\text { Inflow rate, } q_{n} \\
\text { Infiltration } \\
\text { constant, } K \\
\left(\mathrm{~m} \text { min }{ }^{-a}\right) \\
\text { Infiltration } \\
\text { exponent, } a \\
\text { Depth at the } \\
\text { upstream end, } G(m) \\
\text { Manning's roughness } \\
\text { coefficient, } n_{m} \\
\left(\mathrm{~m}^{-1 / 3} \mathrm{~s}\right) \\
\text { Chezy's roughness } \\
\text { coefficient, } C_{h} \\
\left.\text { ( } \mathrm{m}^{-1 / 2} \mathrm{~s}^{-1}\right) \\
\text { Border bed slope, } S_{o} \\
\text { Kinematic friction, } \\
\left.\text { (m-1:3 min }{ }^{-1}\right) \\
\text { Border length, } L(m) \\
\text { Length of one } \\
\text { reach ( } m \text { ) } \\
\text { Length from the } \\
\text { upstrcam cnd wherc } \\
\text { impounding starts } \\
\text { Duration of irrigation } \\
\text { (min) } \\
\text { Number of stations }\end{array}$ & $\begin{array}{c}0.114 \\
\\
5.07 \\
0.005 \\
37.1 \\
100.0 \\
10.0\end{array}$ & $\begin{array}{c}0 \cdot 132 \\
\\
4 \cdot 32 \\
0 \cdot 005 \\
\\
32 \cdot 0 \\
100 \cdot 0 \\
10 \cdot 0\end{array}$ & $\begin{array}{r}0 \cdot 363 \\
0 \cdot 005 \\
\\
27 \cdot 6 \\
100 \cdot 0 \\
\\
10 \cdot 0\end{array}$ & $\begin{array}{c}5 \cdot 10 \\
0 \cdot 003 \\
28 \cdot I \\
100 \cdot 0 \\
10 \cdot 0\end{array}$ & $\begin{array}{c}4 \cdot 10 \\
0.003 \\
\\
22.7 \\
100 \cdot 0 \\
10 \cdot 0\end{array}$ & $\begin{array}{c}0 \cdot 189 \\
\\
3 \cdot 10 \\
0 \cdot 003 \\
17 \cdot 5 \\
100 \cdot 0 \\
\\
10 \cdot 0\end{array}$ & $\begin{array}{c}4.4 \mathrm{I} \\
0 \cdot 00 \mathrm{I} \\
\\
13 \cdot 0 \\
100 \cdot 0 \\
10 \cdot 0\end{array}$ & $\begin{array}{c}5 \cdot 26 \\
0 \cdot 001 \\
16 \cdot 3 \\
100 \cdot 0 \\
10 \cdot 0\end{array}$ & $\begin{array}{r}4.57 \\
0.001 \\
14.6 \\
100.0 \\
10.0\end{array}$ \\
\hline
\end{tabular}

in which

$$
\begin{aligned}
& F_{o}^{2}=\frac{V_{o}^{2}}{g G} \\
& K_{1}=\frac{S_{o} X_{o}}{G F_{o}^{2}} \\
& K_{2}=\frac{a K^{*}}{2} \\
& K^{*}=\frac{K T_{o}^{2}}{G}
\end{aligned}
$$

Here $F_{o}$ is Froude number, $g$ is acceleration due to gravity, $K^{*}$ is dimensionless infiltration constant, $K_{1}$ is kinematic flow number, $K_{2}$ is dimensionless number corresponding to the momentum term associated with infiltration, $P_{1}$ is modified kinematic flow number, and $P_{2}$ is modified dimensionless number corresponding to the momentum term associated with infiltration. 
TABLE 4

Dimensionless parameters in Eqns 15-20

\begin{tabular}{|c|c|c|c|c|c|c|c|}
\hline \multirow{2}{*}{ Data sel } & \multicolumn{7}{|c|}{ Dimensionless parameters } \\
\hline & $a$ & $F_{0}$ & $K_{1}$ & $P_{1}$ & $K^{*}$ & $K_{2}$ & $P_{2}$ \\
\hline Roth-8 & 0.44 & $0 \cdot 30$ & $15 \cdot 79$ & $1 \cdot 38$ & 1.00 & 0.22 & 0.019 \\
\hline Roth-9 & 0.34 & $0 \cdot 16$ & $45 \cdot 53$ & $1 \cdot 16$ & 1.00 & $0 \cdot 17$ & 0.004 \\
\hline Roth-10 & 0.11 & 0.23 & $21 \cdot 46$ & 1.08 & 1.00 & 0.06 & 0.003 \\
\hline Roth-11 & 0.25 & 0.19 & $27 \cdot 01$ & 0.96 & $1 \cdot 00$ & 0.13 & 0.005 \\
\hline $\mathrm{K}-1$ & $0 \cdot 24$ & 0.04 & 29920.00 & $51 \cdot 35$ & $1 \cdot 00$ & 0.12 & 0.000 \\
\hline $\mathrm{K}-2$ & 0.26 & 0.03 & 6214.50 & 6.03 & 1.00 & 0.13 & 0.000 \\
\hline K-3 & $0 \cdot 16$ & 0.03 & 97438.00 & $1061 \cdot 10$ & 1.00 & $0 \cdot 08$ & 0.000 \\
\hline $\mathrm{K}-4$ & 0.31 & 0.02 & $14963 \cdot 00$ & $8 \cdot 18$ & 1.00 & $0 \cdot 15$ & $0 \cdot 000$ \\
\hline $\mathrm{K}-5$ & 0.43 & 0.04 & $4258 \cdot 00$ & 7.80 & 1.00 & 0.21 & 0.000 \\
\hline$K-6$ & 0.33 & 0.08 & $10927 \cdot 00$ & $60 \cdot 70$ & 1.00 & 0.11 & 0.001 \\
\hline $\mathrm{K}-7$ & $0 \cdot 22$ & $0 \cdot 04$ & 79567.50 & $120 \cdot 50$ & 1.00 & 0.11 & 0.000 \\
\hline $\mathrm{K}-8$ & 0.16 & 0.07 & 254974.00 & $1179 \cdot 00$ & 1.00 & 0.08 & 0.000 \\
\hline K-9 & 0.28 & 0.08 & $2637 \cdot 00$ & $16 \cdot 36$ & 1.00 & 0.14 & $0 \cdot 000$ \\
\hline R-I & 0.57 & 0.21 & $771 \cdot 90$ & $33 \cdot 70$ & 1.00 & 0.28 & 0.012 \\
\hline $\mathrm{R}-2$ & 0.57 & 0.18 & $530 \cdot 80$ & $19 \cdot 40$ & 1.00 & 0.28 & 0.009 \\
\hline $\mathrm{R}-3$ & 0.59 & 0.23 & $245 \cdot 50$ & $13 \cdot 18$ & 1.00 & 0.29 & 0.016 \\
\hline R-4 & 0.61 & 0.13 & $620 \cdot 30$ & 10.49 & 1.00 & 0.30 & 0.005 \\
\hline$R-5$ & 0.59 & 0.11 & $802 \cdot 50$ & $9 \cdot 28$ & 1.00 & 0.29 & 0.003 \\
\hline $\mathrm{R}-6$ & 0.62 & $0 \cdot 10$ & $942 \cdot 30$ & 8.68 & 1.00 & 0.30 & 0.003 \\
\hline R-7 & 0.69 & 0.08 & $425 \cdot 90$ & $2 \cdot 47$ & 1.00 & $0 \cdot 35$ & 0.002 \\
\hline $\mathrm{R}-8$ & 0.69 & 0.08 & $411 \cdot 30$ & $2 \cdot 83$ & $1 \cdot 00$ & 0.35 & 0.002 \\
\hline R-9 & 0.53 & 0.08 & $281 \cdot 41$ & 1.71 & 1.00 & 0.26 & 0.002 \\
\hline R-10 & 0.62 & 0.11 & $1367 \cdot 10$ & 17.92 & 1.00 & 0.31 & 0.004 \\
\hline R-11 & 0.63 & $0 \cdot 10$ & 1904.00 & $18 \cdot 10$ & 1.00 & 0.32 & 0.003 \\
\hline $\mathrm{R}-12$ & 0.53 & 0.08 & $1711 \cdot 77$ & 11.48 & 1.00 & 0.27 & 0.002 \\
\hline$R-13$ & 0.67 & 0.09 & $1120 \cdot 90$ & 8.94 & 1.00 & 0.34 & 0.003 \\
\hline $\mathrm{R}-14$ & $0 \cdot 60$ & 0.07 & 1947.20 & 9.98 & 1.00 & $0 \cdot 30$ & 0.002 \\
\hline$R-15$ & 0.53 & 0.05 & $1745 \cdot 80$ & $5 \cdot 13$ & 1.00 & 0.27 & 0.001 \\
\hline$R-16$ & 0.64 & 0.05 & $1348 \cdot 30$ & 2.67 & 1.00 & 0.32 & 0.001 \\
\hline R-17 & 0.69 & 0.05 & 815.90 & $2 \cdot 30$ & 1.00 & 0.35 & 0.001 \\
\hline R-18 & 0.59 & 0.05 & 921.90 & 1.96 & 1.00 & 0.29 & $0.00 \mathrm{I}$ \\
\hline
\end{tabular}

In border irrigation the Froude number is usually very small. ${ }^{10}$ The acceleration terms in the momentum equation can therefore be neglected and the zero-inertia approximation thereof is sufficiently accurate. If $X_{o}$ is large then the zero-inertia approximation reduces to the kinematic wave approximation. Morris and Woolhiser ${ }^{21}$ found that the $K W$ approximation was sufficiently accurate for $P_{1} \geqslant 5$ where $X_{o}$ was considered as the length of the overland flow plane. Katopodes and Strelkoff ${ }^{10}$ suggested $P_{1} x^{*} \geqslant 100$ for the $K W$ model to be accurate for border irrigation.

To evaluate the accuracy of the $K W$ model employed here, $P_{1}$ and $P_{2}$ were computed for each of 31 data sets. Their values along with those of other relevant parameters are given in Table 4. The two parameters $K_{2}$ and $P_{2}$ which are associated with the infiltration term in the momentum equation are very small $\left(0.06 \leqslant K_{2} \leqslant 0.345,0.000 \leqslant P_{2} \leqslant 0.019\right)$. Therefore, their effect on the flow phenomenon is negligible. The values of the Froude number $F_{o}$ are small $\left(0.023 \leqslant F_{o} \leqslant 0 \cdot 296\right)$, $P_{1} \geqslant 5$ and $K_{1}>100$ for a majority of the data sets. However, there are some data sets where the criteria for accuracy of the $K W$ approximation ${ }^{\mathbf{9} 21}$ are not satisfied. It is not clear if the model would be acceptable on these borders from a design standpoint. 


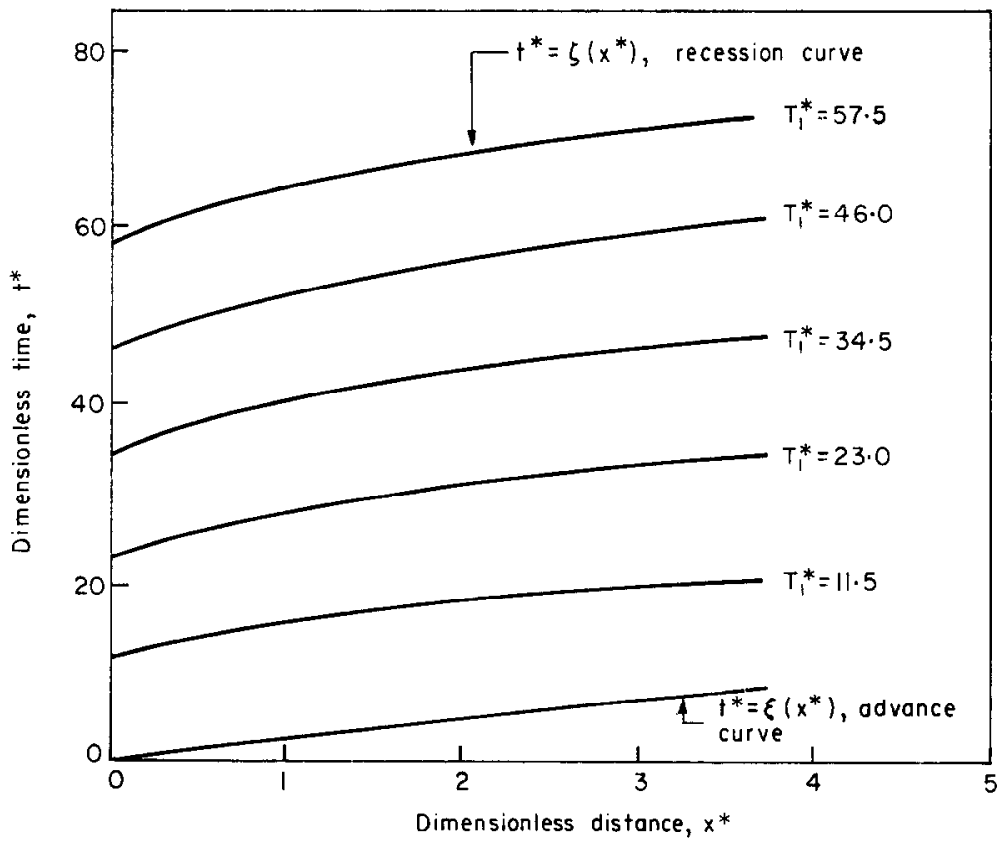

Fig. 1. Dimensionless advance and recession curves for a constant value of $\mathrm{a}=0.2$ in the Kostyakov equation and various durations of irrigation. The advance is computed by the KWT method and the recession by the sequential method

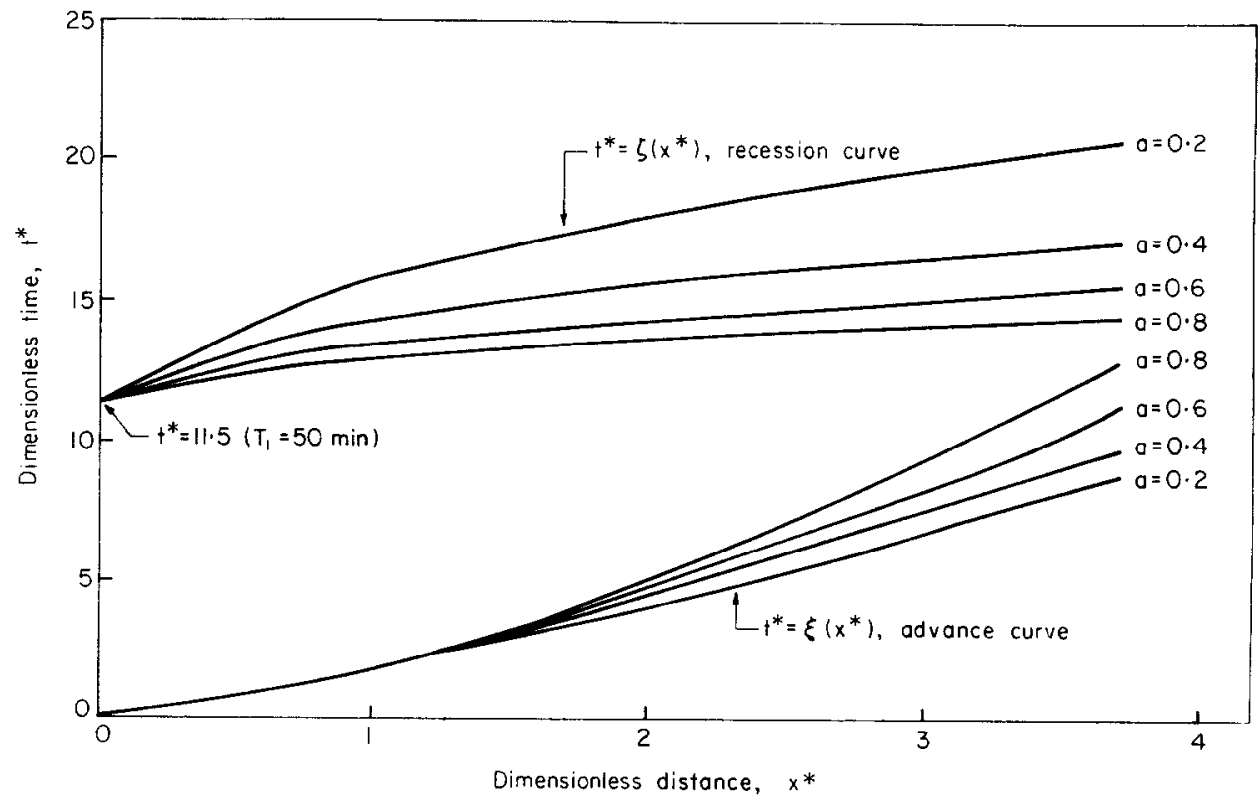

Fig. 2. Dimensionless advance and recession curves for a constant duration of irrigation $\mathrm{t}^{*}=11 \cdot 5$ and various values of $\mathrm{a}$ in the Kosrvakov equation. The advance is computed by the KWT method and the recession by the sequential method 
TABLE 5

Advance and recession times from dimensionless curves

\begin{tabular}{|c|c|c|c|c|c|}
\hline \multirow{3}{*}{$\begin{array}{c}\text { Data } \\
\text { set }\end{array}$} & \multirow{3}{*}{$\begin{array}{l}\text { Dimensionless } \\
\text { distance }\end{array}$} & \multicolumn{4}{|c|}{ Dimensionless time } \\
\hline & & \multicolumn{2}{|c|}{ Advance } & \multicolumn{2}{|c|}{ Recession } \\
\hline & & $\begin{array}{l}\text { From } \\
\text { Fig. } 2\end{array}$ & Observed & $\begin{array}{l}\text { From } \\
\text { Fig. } 2\end{array}$ & Observed \\
\hline Roth-8 & 3.04 & 7.75 & $7 \cdot 75$ & $63 \cdot 7$ & $60 \cdot 5$ \\
\hline Roth-9 & $2 \cdot 75$ & $6 \cdot 37$ & $6 \cdot 34$ & $33 \cdot 5$ & $32 \cdot 7$ \\
\hline Roth-1 I & $3 \cdot 70$ & 8.75 & $9 \cdot 00$ & $48 \cdot 8$ & $49 \cdot 7$ \\
\hline K-5 & 0.15 & 0.21 & 0.17 & $\ldots$ & - \\
\hline K-9 & 0.74 & $1 \cdot 20$ & 0.95 & - & - \\
\hline R-1 & 0.58 & 1.04 & 1.06 & 1.82 & 1.39 \\
\hline $\mathrm{R}-2$ & $1 \cdot 12$ & $2 \cdot 25$ & $2 \cdot 50$ & $4 \cdot 30$ & $3 \cdot 21$ \\
\hline$R-3$ & $2 \cdot 30$ & $5 \cdot 37$ & $6 \cdot 60$ & $10 \cdot 90$ & $12 \cdot 30$ \\
\hline R-4 & 0.57 & 0.85 & 0.77 & $2 \cdot 32$ & 2.08 \\
\hline R-5 & 0.69 & $1 \cdot 20$ & 1.04 & $2 \cdot 80$ & $2 \cdot 52$ \\
\hline R-6 & 0.90 & $1 \cdot 60$ & 1.55 & $4 \cdot 30$ & 3.62 \\
\hline R-7 & 0.24 & $0 \cdot 30$ & 0.23 & 1.79 & 1.79 \\
\hline $\mathrm{R}-8$ & 0.36 & 0.48 & 0.46 & $2 \cdot 30$ & $2 \cdot 26$ \\
\hline$R-9$ & 0.75 & $1 \cdot 30$ & 1.38 & $6 \cdot 30$ & $5 \cdot 64$ \\
\hline$R-10$ & 0.51 & 0.75 & 0.71 & $2 \cdot 26$ & 1.89 \\
\hline R-11 & 0.55 & 0.82 & 0.78 & $2 \cdot 37$ & 1.92 \\
\hline R-12 & 1.01 & 1.90 & 1.68 & 5.00 & 3.72 \\
\hline R-13 & $0 \cdot 37$ & 0.50 & 0.45 & $2 \cdot 32$ & $1 \cdot 86$ \\
\hline R-14 & 0.42 & 0.56 & 0.51 & 1.66 & 1.72 \\
\hline R-15 & 0.89 & 1.55 & $1 \cdot 35$ & $4 \cdot 80$ & 3.81 \\
\hline R-18 & 0.35 & 0.50 & 0.40 & $2 \cdot 70$ & $2 \cdot 74$ \\
\hline
\end{tabular}

\section{Dimensionless advance and recession}

For a fixed value of $n$ ( $n=5 / 3$ for Manning's equation and $n=3 / 2$ for Chezy's equation) the only unknown parameter appearing explicitly in Eqns 11 and 12 is a if we seek the solution for advance. However, if the solutions are extended to calculate recession, the duration of irrigation will also enter as another parameter in solutions for the complete irrigation cycle.

Fig. 1 shows a plot between dimensionless distance $x^{*}$ and time $t^{*}$ for various durations of irrigation $T_{1}^{*}$ for a specified value of $a=0 \cdot 2$. We get only one advance curve but a number of recession curves corresponding to different values of $T_{1}^{*}$. All the recession curves are approximately parallel and can therefore be transferred to a single recession curve for a specified parameter $a$. By keeping $T_{1}^{*}=11 \cdot 5$, the dimensionless advance and recession curves were derived by varying $a$ from $0 \cdot 2$ to 0.8 as shown in Fig. 2. For any other $T_{1}^{*}$ the recession curve can be shifted parallel to the recession curve of Fig. 2 corresponding to the given parameter $a$. To test the accuracy of these dimensionless curves, the values of $t^{*}$ at some $x^{*}$ for different data sets were read from Fig. 2 and are given along with observed $t^{*}$ in Table 5. The values of $t^{*}$ read from the figure and those observed for the same values of $x^{*}$ agree quite closely. This shows that these dimensionless curves are sufficiently accurate. However, their validity still remains to be tested for all possible applicable ranges of input data.

\section{Application to border irrigation design}

To design an irrigation border the variables assumed to be known are: (1) depth of water to be applied in the root zone; (2) soil infiltration characteristics; (3) border bed roughness, and (4) the 
initial and boundary conditions. The unknown variables are: (1) inflow rate; (2) duration of irrigation; (3) length of the border, and (4) infiltrated depth of water. The inflow rate, duration of irrigation and length of the border are adjusted to match the advance and recession curves. This affects the infiltrated depth of water and the depth of water stored in the root zone and in turn the irrigation efficiencies corresponding to the specified depth of water application.

The procedure for design of border irrigation is as follows.

(1) Depth of water to be applied in the root zone can be calculated by using the following relationship:

$$
d_{n}=\frac{P_{w} A_{s} D_{r}}{100}
$$

where $d_{n}$ is depth of water needed in the root zone. $A_{s}$ bulk density of soil, $P_{w}$ soil moisture deficit in percent and $D_{r}$ depth of root zone.

(2) We assume that inflow rate $q_{o}$ is known.

(3) We determine advance and recession curves as described previously.

(4) Although there are various ways of expressing irrigation efficiencies, ${ }^{22-32}$ we compute them by using the following most commonly used equations: ${ }^{22}$

$$
\begin{gathered}
\text { Application efficiency, } E_{\mathfrak{a}}=100 \frac{d_{s}}{d_{a}} \\
\text { Distribution efficiency, } E_{d}=100\left(1-\frac{d_{d}}{d_{s}}\right) \\
\text { Storage efficiency, } E_{s}=100 \frac{d_{s}}{d_{n}}
\end{gathered}
$$

where $d_{s}$ is average depth of water stored in root zone, $d_{a}$ is depth of water applied, and $d_{d}$ is average absolute numerical deviation of stored depth from $d_{s}$ along the border. The depth of water infiltrated along the border length and stored in the root zone can be calculated from Eqn 4. The opportunity time is obtained from advance and recession curves determined in step (3).

(5) If the computed efficiencies are at least equal to the efficiencies desired, the design is completed and the length of the border and the duration of irrigation as assumed in step (3) are sufficient. However, if the efficiencics are less than desircd, we change duration of irrigation and repeat steps (3)-(5).

(6) We continue steps (3)-(5) until the desired irrigation efficiencies are achieved. If efficiencies are less than desired, we change the border length and continue steps (3)-(6); otherwise the design is completed.

\section{Validation of design procedure}

Irrigation efficiencies were used to validate the design procedurc. These cfficiencics are measures of the effective utilization of the water applied to the border. The observed and computed irrigation efficiencies for all the data sets in Tables 1-3 are given in Tables 6-7. For the data sets K-1-K-9 there are no observed efficiencies. For the data sets Roth-8-Roth-11, the observed and computed distribution efficiencies compare with a difference of less than $8 \%$. The observed and computed application efficiencies compare equally well with a difference of less than $9 \%$. Likewise, the observed and computed storage efficiencies differ by about $11 \%$. For the data sets $\mathrm{R}-1-\mathrm{R}-18$, the difference between observed and computed results ranges up to about 
TABLE 6

Irrigation efficiencies on the basis of calculated and observed advance and recession times (min) for a total depth of application of $0 \cdot 1 \mathrm{~m}$ for freely draining borders

\begin{tabular}{|c|c|c|c|c|c|c|}
\hline \multirow{3}{*}{$\begin{array}{c}\text { Data } \\
\text { set }\end{array}$} & \multicolumn{6}{|c|}{ Efficiencies } \\
\hline & \multicolumn{3}{|c|}{ Observed } & \multicolumn{3}{|c|}{$\begin{array}{c}\text { Calculated } \\
\text { kinematic model }\end{array}$} \\
\hline & $E_{\boldsymbol{r}}$ & $E_{d}$ & $E_{s}$ & $E_{a}$ & $E_{d}$ & $E_{s}$ \\
\hline Roth-8 & $40 \cdot 01$ & $91 \cdot 67$ & $83 \cdot 57$ & $44 \cdot 09$ & $99 \cdot 05$ & 92.08 \\
\hline Roth-9 & $28 \cdot 24$ & 91.67 & $80 \cdot 44$ & $31 \cdot 12$ & 99.57 & $88 \cdot 64$ \\
\hline Roth-10 & $10 \cdot 12$ & $91 \cdot 57$ & $39 \cdot 85$ & $11 \cdot 18$ & $99 \cdot 50$ & 43.99 \\
\hline Roth-11 & $21 \cdot 15$ & 91.67 & $60 \cdot 42$ & $23 \cdot 54$ & $99 \cdot 71$ & 66.66 \\
\hline $\mathrm{K}-1$ & - & - & - & $45 \cdot 12$ & $95 \cdot 28$ & 33.43 \\
\hline $\mathrm{K}-2$ & - & - & - & $63 \cdot 05$ & $96 \cdot 87$ & $58 \cdot 33$ \\
\hline $\mathrm{K}-3$ & - & - & - & $57 \cdot 01$ & 96.71 & $45 \cdot 06$ \\
\hline $\mathrm{K}-4$ & - & - & - & $47 \cdot 68$ & 96.43 & 69.77 \\
\hline $\mathrm{K}-5$ & - & - & - & $76 \cdot 01$ & 96.02 & $55 \cdot 30$ \\
\hline$K-6$ & - & - & - & 39.96 & $95 \cdot 04$ & 36.82 \\
\hline $\mathrm{K}-7$ & - & - & - & $56 \cdot 10$ & $96 \cdot 32$ & 54.09 \\
\hline $\mathrm{K}-8$ & - & - & - & $47 \cdot 98$ & $97 \cdot 44$ & $48 \cdot 08$ \\
\hline $\mathrm{K}-9$ & - & - & - & $53 \cdot 59$ & $100 \cdot 00$ & $100 \cdot 00$ \\
\hline
\end{tabular}

TABLE 7

Irrigation efficiencies on the basis of calculated and observed advance and recession times (min) for a total depth of application of $0 \cdot 1 \mathrm{~m}$ for closed end borders

\begin{tabular}{|c|c|c|c|c|c|c|}
\hline \multirow{3}{*}{$\begin{array}{c}\text { Duta } \\
\text { set }\end{array}$} & \multicolumn{6}{|c|}{ Efficiencies } \\
\hline & \multicolumn{3}{|c|}{ Observed } & \multicolumn{3}{|c|}{$\begin{array}{c}\text { Calculated } \\
\text { kinematic model }\end{array}$} \\
\hline & $E_{a}$ & $E_{d}$ & $E_{s}$ & $E_{a}$ & $E_{d}$ & $E_{s}$ \\
\hline R-I & 87.99 & $54 \cdot 33$ & $31 \cdot 72$ & $69 \cdot 47$ & $94 \cdot 92$ & $25 \cdot 04$ \\
\hline $\mathrm{R}-2$ & $97 \cdot 02$ & $64 \cdot 29$ & 43.08 & $79 \cdot 36$ & $90 \cdot 02$ & $35 \cdot 24$ \\
\hline R-3 & $95 \cdot 50$ & 86.67 & 44.96 & $100 \cdot 00$ & $90 \cdot 12$ & $47 \cdot 46$ \\
\hline $\mathrm{R}-4$ & 94.66 & $65 \cdot 46$ & $53 \cdot 84$ & 74.67 & $90 \cdot 41$ & $42 \cdot 47$ \\
\hline R-5 & 91.71 & $69 \cdot 45$ & 55.02 & $77 \cdot 24$ & $90 \cdot 88$ & $46 \cdot 34$ \\
\hline $\mathrm{R}-6$ & 85.03 & $86 \cdot 13$ & $50 \cdot 21$ & $83 \cdot 44$ & $89 \cdot 98$ & $47 \cdot 27$ \\
\hline $\mathrm{R}-7$ & $92 \cdot 14$ & $85 \cdot 50$ & $73 \cdot 81$ & 77.93 & $92 \cdot 38$ & $62 \cdot 43$ \\
\hline $\mathrm{R}-8$ & $85 \cdot 13$ & 89.81 & $60 \cdot 27$ & $79 \cdot 05$ & $91 \cdot 24$ & 55.97 \\
\hline R-9 & $89 \cdot 91$ & 91.67 & $68 \cdot 16$ & $86 \cdot 15$ & $90 \cdot 26$ & $65 \cdot 31$ \\
\hline$R-10$ & $81 \cdot 32$ & $71 \cdot 86$ & $53 \cdot 41$ & $70 \cdot 08$ & 92.63 & 46.03 \\
\hline R-11 & $78 \cdot 27$ & $76 \cdot 88$ & $47 \cdot 90$ & $72 \cdot 59$ & $92 \cdot 45$ & 44.43 \\
\hline R-12 & $83 \cdot 10$ & $88 \cdot 72$ & $49 \cdot 73$ & $84 \cdot 79$ & $90 \cdot 52$ & $50 \cdot 75$ \\
\hline $\mathrm{R}-13$ & $70 \cdot 42$ & $91 \cdot 67$ & $56 \cdot 41$ & $71 \cdot 70$ & 93.63 & 57.43 \\
\hline R-14 & $77 \cdot 34$ & $81 \cdot 01$ & $55 \cdot 68$ & $68 \cdot 64$ & $92 \cdot 73$ & $49 \cdot 42$ \\
\hline R-15 & 86.54 & 90.99 & $66 \cdot 30$ & 86.59 & $90 \cdot 00$ & $66 \cdot 34$ \\
\hline R-16 & $84 \cdot 28$ & $85 \cdot 80$ & $81 \cdot 01$ & 65.93 & $94 \cdot 20$ & $63 \cdot 38$ \\
\hline R-17 & 83.03 & 91.41 & $76 \cdot 72$ & $75 \cdot 92$ & 91.83 & $70 \cdot 15$ \\
\hline R-18 & 83.80 & 91.67 & $70 \cdot 21$ & $82 \cdot 38$ & $91 \cdot 24$ & $69 \cdot 03$ \\
\hline
\end{tabular}


$25 \%$ for application efficiency, up to about $80 \%$ for distribution efficiency and up to about $15 \%$ for storage efficiency. It is not surprising that the $K W$ model does not predict distribution efficiency as accurately as application and storage efficiencies, for the depth, as a function of time, over the border is not modelled accurately. ${ }^{6}$ This is partly because the depth of flow involved is quite small. This comparison suggests that the design procedure based on the $K W$ model is reasonably accurate for purposes of border irrigation design if application and storage efficiencies are the governing considerations. This would not be true if the distribution efficiency is the controlling factor.

\section{An example of border irrigation design}

Let us assume that the infiltration characteristics of the soil, bed roughness and slope, inflow rate and the depth of water needed in the root zone are known. We want to determine the length of the border and duration of irrigation to obtain application, distribution and storage efficiencies above $90 \%$ for freely draining borders. We determine the border length and duration of irrigation as follows.

TABLE 8

Irrigation efficiencies by kinematic wave model for the data set Roth-9 for various lengths of border and durations of irrigation. Depth of water needed in root zone $=8 \mathrm{~cm}$

\begin{tabular}{|c|c|c|c|c|c|c|c|c|c|}
\hline \multirow{3}{*}{$\begin{array}{l}\text { Length of } \\
\text { border, } m\end{array}$} & & & & \multicolumn{3}{|c|}{ Duration of irrigation, min } & & & \\
\hline & \multicolumn{3}{|c|}{100} & \multicolumn{3}{|c|}{120} & \multicolumn{3}{|c|}{140} \\
\hline & $E_{a}$ & $E_{d}$ & $E_{s}$ & $E_{a}$ & $E_{d}$ & $E_{s}$ & $E_{a}$ & $E_{d}$ & $E_{\mathrm{s}}$ \\
\hline $\begin{array}{r}80 \\
100 \\
120 \\
140 \\
160 \\
180 \\
200\end{array}$ & $\begin{array}{r}40 \cdot 71 \\
50 \cdot 21 \\
60 \cdot 25 \\
70 \cdot 29 \\
80 \cdot 33 \\
90 \cdot 37 \\
100 \cdot 00\end{array}$ & $\begin{array}{l}98.13 \\
98.95 \\
98.95 \\
98.95 \\
98.95 \\
98.95 \\
98.95\end{array}$ & $\begin{array}{l}92 \cdot 12 \\
90 \cdot 90 \\
90 \cdot 90 \\
90 \cdot 90 \\
90 \cdot 90 \\
90 \cdot 90 \\
90 \cdot 90\end{array}$ & $\begin{array}{l}35 \cdot 82 \\
44 \cdot 52 \\
53 \cdot 42 \\
62 \cdot 32 \\
71 \cdot 23 \\
80 \cdot 13 \\
89 \cdot 03\end{array}$ & $\begin{array}{l}99 \cdot 11 \\
99 \cdot 21 \\
99 \cdot 21 \\
99 \cdot 21 \\
99 \cdot 21 \\
99 \cdot 21 \\
99 \cdot 21\end{array}$ & $\begin{array}{l}97 \cdot 27 \\
96 \cdot 71 \\
96 \cdot 71 \\
96 \cdot 71 \\
96 \cdot 71 \\
96 \cdot 71 \\
96 \cdot 71\end{array}$ & $\begin{array}{l}31 \cdot 56 \\
39 \cdot 45 \\
37 \cdot 34 \\
55 \cdot 24 \\
63 \cdot 13 \\
71 \cdot 02 \\
78 \cdot 91\end{array}$ & $\begin{array}{l}100 \cdot 00 \\
100 \cdot 00 \\
100 \cdot 00 \\
100 \cdot 00 \\
100 \cdot 00 \\
100 \cdot 00 \\
100 \cdot 00\end{array}$ & $\begin{array}{l}100 \cdot 00 \\
100 \cdot 00 \\
100 \cdot 00 \\
100 \cdot 00 \\
100 \cdot 00 \\
100 \cdot 00 \\
100 \cdot 00\end{array}$ \\
\hline \multirow{4}{*}{200} & & & & \multicolumn{3}{|c|}{ Duration of irrigation, min } & & & \\
\hline & \multicolumn{3}{|c|}{160} & \multicolumn{3}{|c|}{180} & \multicolumn{3}{|c|}{200} \\
\hline & & & & \multicolumn{3}{|c|}{ Efficiencies percentage } & & & \\
\hline & $E_{a}$ & $E_{d}$ & $E_{\mathrm{s}}$ & $E_{\mathrm{a}}$ & $E_{d}$ & $E_{s}$ & $E_{a}$ & $E_{d}$ & $E_{s}$ \\
\hline 80 & 27.62 & $100 \cdot 00$ & $100 \cdot 00$ & $24 \cdot 55$ & $100 \cdot 00$ & $100 \cdot 00$ & $22 \cdot 09$ & $100 \cdot 00$ & $100 \cdot 00$ \\
\hline 100 & $34 \cdot 52$ & $100 \cdot 00$ & $100 \cdot 00$ & $30 \cdot 69$ & $100 \cdot 00$ & $100 \cdot 00$ & $27 \cdot 62$ & $100 \cdot 00$ & $100 \cdot 00$ \\
\hline 120 & 41.43 & $100 \cdot 00$ & $100 \cdot 00$ & $36 \cdot 82$ & $100 \cdot 00$ & $100 \cdot 00$ & $33 \cdot 14$ & 100.00 & $100 \cdot 00$ \\
\hline 140 & $48 \cdot 33$ & $100 \cdot 00$ & $100 \cdot 00$ & $42 \cdot 96$ & $100 \cdot 00$ & $100 \cdot 00$ & $38 \cdot 66$ & $100 \cdot 00$ & $100 \cdot 00$ \\
\hline 160 & $55 \cdot 24$ & 100.00 & $100 \cdot 00$ & $49 \cdot 10$ & $100 \cdot 00$ & $100 \cdot 00$ & $44 \cdot 19$ & $100 \cdot 00$ & $100 \cdot 00$ \\
\hline 180 & $62 \cdot 14$ & $100 \cdot 00$ & $100 \cdot 00$ & $55 \cdot 24$ & $100 \cdot 00$ & $100 \cdot 00$ & $49 \cdot 71$ & $100 \cdot 00$ & $100 \cdot 00$ \\
\hline 200 & 69.04 & $100 \cdot 00$ & $100 \cdot 00$ & $61 \cdot 37$ & $100 \cdot 00$ & $100 \cdot 00$ & $55 \cdot 24$ & $100 \cdot 00$ & $100 \cdot 00$ \\
\hline
\end{tabular}


For purposes of illustration, we use the data set Roth- 9 and calculate irrigation efficiencies following the procedure outlined for the $K W$ model. The efficiencies for $8 \mathrm{~cm}$ of depth of water application are given in Table 8 . We see that a border length of $200 \mathrm{~m}$ and duration of irrigation of $100 \mathrm{~min}$ gives irrigation efficiencies above $90 \%\left(E_{a}=100 \cdot 0, E_{d}=98 \cdot 95, E_{s}=90 \cdot 90\right)$, if the $K \mathrm{~W}$ model is used. For any other sets of efficiencies, the border length and duration of irrigation can be chosen from Table 8 .

\section{Conclusions}

(1) The $K W$ model is sufficiently accurate for modelling border irrigation for a majority of the data sets used in this study.

(2) One-parameter family of curves for advance as well as for recession can be generated for ready use in irrigation design. A sample of such curves has been presented in this study.

(3) The application and storage efficiencies computed by the model agree reasonably well with those observed on experimental borders. However, this is not the case with distribution efficiency.

(4) The design procedure, based on the $K W$ model, can be reasonably accurate if application and storage efficiencies are the governing considerations.

\section{Acknowledgements}

This study was supported in part by funds provided by National Science Foundation under the project, Free Boundary Problems in Water Resource Engineering, ENG79-23345.

\section{REFERENCES}

1 Ram, R. S. Mathematical modeling of surface irrigation. Unublished Ph.D. dissertation, Mississippi State University, 1982

2 Bassett, D. L.: Fangmeier, D. D.; Strelkoff, T. Hydraulics of surface irrigation. In Design and Operation of Farm Irrigation Systems (M. E. Jensen, Ed.), 447-498. St Joseph, Michigan: American Society of Agricultural Engineers

${ }^{3}$ Sherman, B.; Singh, V. P. A kinematic model for surface irrigation. Water Resources Res., 197814 (2) 357-364

4 Sherman, B.; Singh, V. P. A kinematic model for surface irrigation: an extension. Water Resources Res., $198218(3) 659-667$

5 Singh, V. P.; Sherman, B. A kinematic study of surface irrigation: mathematical solutions. Tech. Report WRR4, Water Resources Program, Department of Civil Engineering, Louisiana State University, 1983

6 Singh, V. P.; Ram, R. S. A kinematic model for surface irrigation: verification by experimental data. Water Resources Res., 198319 (6) 1599-1612

7 Smith, R. E. Border irrigation advance and ephemeral flood waves. J. Irrig. Drain. Divn, Proc. Am. Soc. Civil Engrs, 197298 (IR2) 289-307

a Chen, B. J.; McCann, R. C; Singh, V. P. Numerical solutions to the kinematic model of surface irrigation. Tech. Rep. MSSU-EIRS-CE-81-1, Engineering and Industrial Research Station, Mississippi State University, 1981

- Woolhiser, D. A.; Liggett, J. A. Unsteady, one-dimensional flow over a plane-the rising hydrograph. Water Resources Res., 19673 (3) 753-771

10 Katopodes, N. D.; Strelkoff, I. Dimensionless solutions of border irrigation advance. J. Irrig. Drain. Div, Proc. Am. Soc. Civil Engrs 1977103 (IR4) 401-417

11 Chen, C. L. Surface irrigation using kinematic-wave method. J. Irrig. Drain. Div., Proc. Am. Soc. Civil Engrs, 197096 (IR 1) 39-48

12 Woolhiser, D. A. Discussion of "surface irrigation using kinematic-wave method by C. L. Chen". J. Irrig. Drain. Div., Proc. Am. Soc. Civil Engrs, 197096 (IR4) 498-500

13 Cunge, J. A.; Woolhiser, D. A. Irrigation systems. In Unsteady Flow in Open Channels (K. Mahmood and V. Yevjevieh, Eds). Fort Collins, Colorado: Water Resources Publications, 1975 522-537 
14 Ram, R. S.; Singh, V. P.; Prasad, S. N. Mathematical modeling of border irrigation. Water Resources Rep. No. 5, Department of Civil Engineering, Louisiana State University, 1983

15 Kostyskov, A. N. On the dynamics of the coefficient of water percolation in soils and of the necessity of studying it from a dynamic point of view for purposes of amelioration. Trans. Sixth Comm. Int. Soc. Soil Sci 1932, 17-21 (in Russian)

16 Roth, R. L. Roughness during border irrigation. Unpublished M.S. thesis, University of Arizona, 1971

17 Roth, R. L.: Fonken, D. W.; Fangmeier, D. D.; Atchison, K. T. Data for border irrigation models. Trans. Am. Soc. Agric. Engrs, 19748 157-161.

${ }^{18}$ Kincaid, D. F. Hydrodynamics of border irrigation. Unpublished Ph.D. dissertation, Colorado State University, 1970

19 Ram, R. S. Hydraulics of recession flow in border irrigation system. Unpublished M.S. thesis, Indian Institute of Technology, Kharagpur, India, 1969

${ }^{20}$ Ram, R. S. Comparison of infiltration measurement techniques. J. Agric. Engng, 19729 (2) 67-75

21 Morris, E. M.; Woolhiser, D. A. Unsteady, one-dimensional flow over a plane: partial equilibrium and recession hydrographs. Water Resources Res., 198016 (2) 355-360

22 Hansen, V. E. New concepts in irrigation efficiency. Trans. Am. Soc. Agric. Engrs, 1960 3(1) $55-67$. 61-64

${ }^{23}$ Keller, J. Effect of irrigation method on water conservation. J. Irrig. Drain. Divn, Proc. Am. Soc. Civil Engrs, 196584 (IR3) 61071

24 Smerdon, E. T.; Glass, L. J. Surface irrigation water distribution efficiency related to soil infiltration. Trans. Am. Soc. Agric. Engrs, 196583 (1) 76-78, 82

25 Erie, L. Management: a key to irrigation efficiency. J. Irrig. Drain. Divn, Proc. Am. Soc. Civil Engrs, 196894 (IR3) 285-293

26 Jensen, M. E. Evaluating irrigation efficiency. J. Irrig. Drain. Divn, Proc. Am. Soc. Civil Engrs, 196793 (IR1) 83-98

27 Willardson, L. S.; Bishop, A. A. Analysis of surface irrigation application efficiency. J. Irrig. Drain. Divn, Proc. Am. Soc. Civil Engrs, 196793 (2) 21-35

${ }^{28}$ Fok, Y. S.; Bishop, A. A. Expressing irrigation efficiency in terms of application time, intake and water advance constants. Trans. Am. Soc. Agric. Engrs, 196912 (4) $438-442$

29 Salazar, L. J. Spatial distribution of applied water in surface irrigation. Unpublished M.S. thesis. Colorado State University, 1977

30 Karmeli, D. Distribution patterns and losses for furrow irrigation. J. Irrig. Drain. Divn. Proc. Am. Soc. Civil Engrs, 1978104 (IR1) 59-68

31 On-Farm Irrigation Committee. Describing irrigation efficiency and uniformity. J. Irrig. Drain. Divn. Proc. Am. Soc. Civil Engrs, 1978104 (1) 35-40

32 Norum, D. I.; Peri, G.; Hart, W. E. Application of system optimal depth concept. J. Irrig. Drain. Divn, Proc. Am. Soc. Civil Engrs, 1979105 (IR4) 357-365 